contributes indirectly to so many other fields.

The problems now facing American scientists and engineers, though vastly greater in scale, are common in advanced industrial countries. There has been a collapse of the academic boom of the 50s and $60 \mathrm{~s}$. Average annual growth at constant prices of funding for academic R\&D from 1953 to 1960 was $12 \%$; from 1960 to $1964,14 \%$; from 1968 to 1974 , zero; and from 1974 to 1978 , about $4 \%$. Despite increased numbers of graduate students, doctorates in science and engineering are declining. Total support for basic academic research declined by $8 \%$ between 1968 and 1976 and federal support by $10 \%$.

Naturally the overwhelming number of developments reported are concerned with practical and, in some cases, urgent problems: energy, material resources and health. Their solution is difficult enough in scientific terms but is increasingly hindered by social and political considerations. These are not only panic reactions as in the case of genetic manipulation or nuclear energy after Harrisburg but arise out of growing concern with environmental questions, leading to regulatory procedures. No doubt there is some special pleading here. Even the possibility of expanding the use of coal is hindered by the opposition of agrarian states to its mining in their territories and by fear of the atmospheric effects of its use in power stations. For this reason conservation is priority number one in the energy field. Of course vested interests are involved and indications of these can be detected in some of the reports. Political decisions can also distort the allocation of $R \& D$ resources, tactfully referred to in an account of the examination by "a new leadership" of the "enormous effort" of Nixon's "War on Cancer" in order to achieve a more balanced programme.

Many readers of this fascinating book must be left with two impressions: the enormous area remaining for scientific R\&D to deal with the world's material problems and search for knowledge; and, in a divided world, the considerable international cooperation here reported and the need and scope for its further enlargement.

Austen Albu was a Member of Parliament from 1948 to 1974, and a Visiting Research Fellow of the University of Sussex Science Policy Unit, Brighton, UK, from 1975 to 1979.

\section{Bringing Man poetically to life}

\section{Yves Coppens}

The People of the Lake: Man, His Origins, Nature and Future. By Richard E. Leakey and Roger Lewin. Pp.223. (Collins: London; Doubleday: New York, 1979.) $£ 6.50$.

People of the Lake is a kind of essay on Man. Pleasantly readable, it puts forward in a little over 200 pages an overall view of our species in both a historical and comparative context which is thoroughly satisfying for anyone with a naturalist's turn of mind. Although the reader may regret a certain lack of rigour in the comparative approach, as too great an emphasis is placed on seeking out good examples to back up the argument at the expense of a critical attitude towards similarities and differences, the attempt is nevertheless an extremely interesting one, and one worthy of being encouraged.

Divided into 11 chapters, the book is in fact made up of two sections of almost equal length; the first of these, comprising the first five chapters and part of the eleventh, is devoted to palaeontology, the origin and evolution of Man, from the first primates of $70 \mathrm{Myr}$ ago to Homo sapiens sapiens; the second (Chapters 6, 7, 8, 9, 10 and the remainder of Chapter 11) concerns itself with ethology, human behaviour and the search within the animal kingdom for Man's origins and the direction of his evolution. Given the training and special interests of the authors, this second part is more an essay in prehistoric ethology: just like chimpanzees, gorillas, baboons or geladas, contemporary Man is used in an attempt to reconstruct the lifestyle, psychology and behaviour of ancient Man. In spite of what might be inferred from the sub-title, neither the future of mankind, nor even his present condition, seem to be the writers' principal concern.

The point of departure - hence the title - is the palaeontological research carried out by Richard Leakey over the past 12 years on the shores of Lake Turkana in Kenya. In 1967, Richard Leakey, together with Francis Clark Howell and myself and initially Louis Leakey, his father, and Camille Arambourg - played a part in setting up the important international expedition along the Omo River in Ethiopia, to the north of Lake Turkana itself; and it was during one of the many flights that had to be made back and forth between Nairobi and his camp on the Omo that he noticed the sedimentary formations outcropping on the eastern banks of the lake. He decided there and then to investigate, and since 1968 a dozen or so separate expeditions have provided an extraordinary collection of human fossils, their age ranging from more than $4 \mathrm{Myr}$ to less than $1 \mathrm{Myr}$ and including half a dozen skulls in an excellent state of preservation, highlighted by the famous ER-KNM 406 (Australopithecus boisel), 1470 (Homo habilis) and 3733 (Homo erectus). These expeditions, known as the Koobi Fora Project, make up one of the four largescale international projects under way in the Rift Valley of East Africa and concerned with the problems surrounding the origin of Man. The other three are the Olduvai expedition (more recently Olduvai-Laetoli), originating with Louis Leakey as long ago as 1931 and under the direction initially of Louis Leakey, then of Louis and Mary Leakey and, since Louis' death in 1972, of Mary Leakey alone; the international Omo expedition for which Francis Clark Howell and myself were responsible over eight further seasons after the departure of Richard Leakey in 1968; and the Afar international expedition, which began work in 1972 and has since been under the supervision of Maurice
Taieb, Donald Johanson and myself. The People of the Lake themselves, of course, are these fossil men of about $2 \mathrm{Myr}$ ago (Australopithecus boisei and Homo habilis), whom the authors bring poetically to life again as early as the first chapter of the book, in a reconstructed landscape on the banks of a palaeolithic Lake Turkana.

The palaeontological résumé provided is rather conventional but not without interest. It traces the links between Cretaceous and Quaternary forms, the change from a nocturnal to diurnal life (and the consequent improvement in eyesight), and, much nearer in time to ourselves, the straightening up of the body and its probable successive implications the freeing of the hands, work, development of the sweat glands, loss of hair and the appearance of a protective pigmentation for the body. Considerable passages of the book are devoted to this possible ancestor of Man, the quadruped Ramapithecus, and his erect descendant the Australopithecus, and to the irritating gap of $4 \mathrm{Myr}$ that separates them.

The ethological aspects examined in the second section of the book represent in many cases interesting approaches to problems which are not usually dealt with in the context of prehistory. They all arrive at the same fundamental conclusion: that Man is as he is because at the time of his origin he shared his food with the other people in his group - the development of his intelligence (and of his language, which is no more than a manifestation of his intelligence), the extraordinary transformation of his technology, his inclination for reciprocal altruism and for family life, even his obsession with sex - are the fruits of his cooperative life and of his mixed economy based on the male's hunting and the female's gathering: everyone is in part dependent on others. With this idea established as their foundation, the authors go on to debate a wide range of problems raised, rightly or wrongly, by our times, or by other writers whose success has 
moulded our view of our times: the hypothesis of the essential role of hunting in the evolution of Man, the counterhypothesis of the preponderant role of gathering, the problem of Women's Liberation, the still unsettled question of the origin of aggression and of the phenomenon of war, and so on.

It is unfortunate that these topics are touched on only rather superficially, though it could scarcely be otherwise in such a limited space; from this point of view it must be admitted that the reader's appetite is never entirely satisfied: he is left not wholly convinced by an argument too fragmentary in its evidence. Nonetheless, the very fact that some additional light has been thrown on all these various problems by authors possessing zoological, ethological, prehistorical, palaeontological and ethnological knowledge, obviously deserves a salute. Indeed, a second salute, as I have already stressed the importance of a comparative approach in the introduction to the French edition of the present authors' earlier work Origins (for a review, see Nature 270, 108; 1977).

Nevertheless, I cannot agree with every statement made in this book. It may be instructive to look at some of the points of disagreement. On page 73, the Australopithecus is introduced to us as a possible herbivore although there is little likelihood that it can actually have been one; he was in fact not sufficiently far removed from Man to have had a fundamentally different digestive apparatus. And Man is incapable of digesting cellulose.

Between 1955 and 1960, Johannes Hürzeler, in connection with his study of the Oreopithecus, pointed out the great antiquity of the phenomenon of bipedality in nature. A demonstration (page 70) of the existence of bipedality only $4 \mathrm{Myr}$ ago is not therefore going to come as much of a surprise to vertebrate palaeontologists, who for the past twenty years have been expecting to uncover its existence in the Miocene.

The notion (page 131) that the brain was among the first organs to take on human form, rather than the contrary suggestion, has long prevailed; hence, the celebrated Piltdown hoax of a fossil man with a modern brain and pongid teeth. And when authentic and extremely ancient fossils, such as the first Taung Australopithecus skull, have been brought to light, it has been quickly established that the brain, although of modest development, was different from that of the great apes.

One should not confuse (page 92) written knowledge with the knowledge of nature that can be acquired in the field; any farm worker in any Western country, living in close contact with his surroundings and often hunting game there, would surprise Richard Leakey and Roger Lewin with the quality and diversity of his knowledge of the fauna and flora, even of the very rocks, of the countryside about him.

How is it possible (page 126), in a work

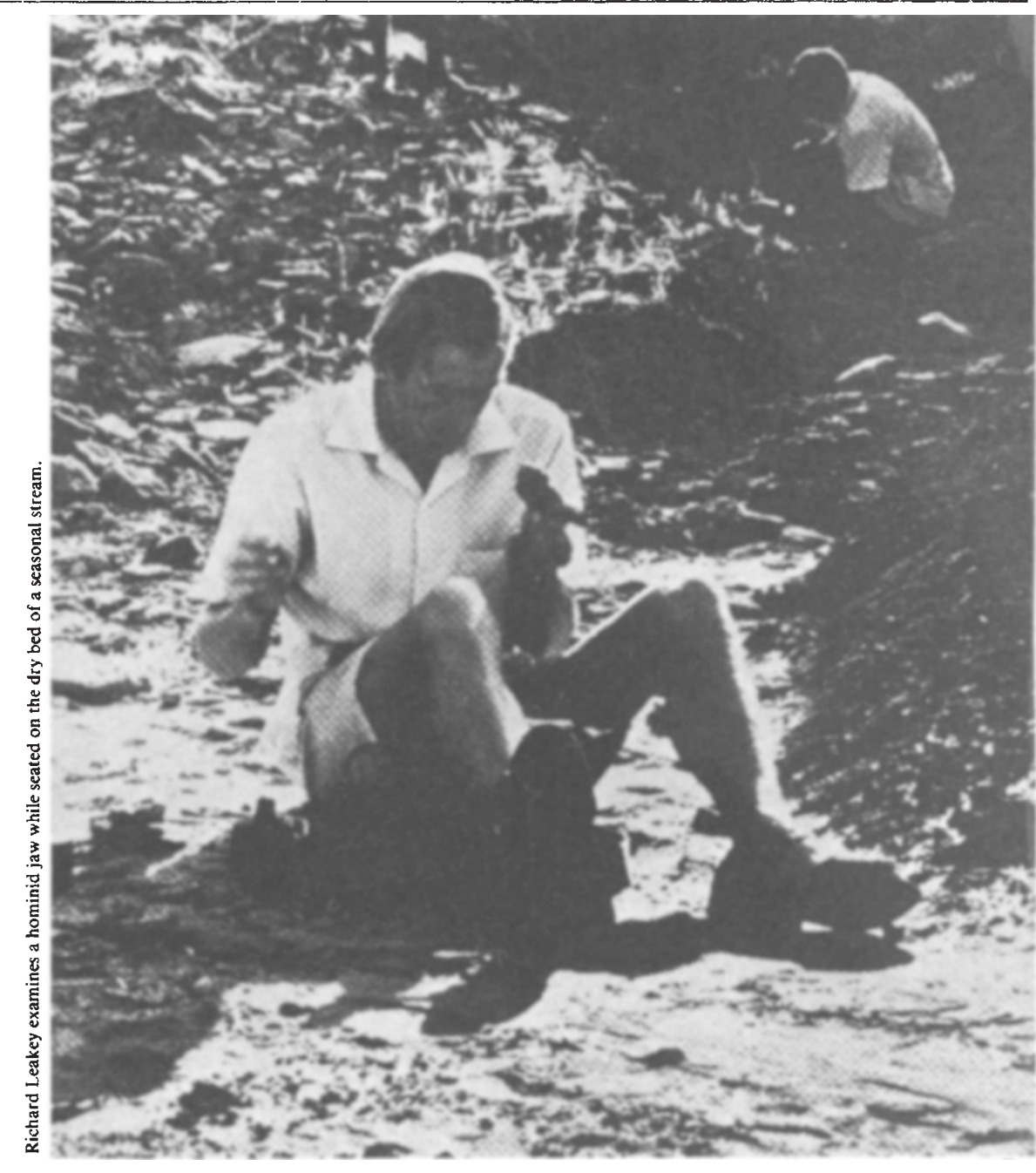

which (rightly) attempts to demonstrate the precarious nature of the borderline between the apes and Man, in respect of the use (and manufacture) of tools and the notion of natural facing elements (the rain dance of the chimpanzees, for instance), to come out with a statement as specific as "we suggest that it was primitive Homo

who made tools and, furthermore, that it was only Homo who did so"'? Why is it not possible that the Australopithecines may have made a beginning which Man inherited and then developed brilliantly? Linking the tool so dogmatically to the genus Homo, the authors throw the definition of the genus into confusion - a definition which should remain strictly biological.

May I finally be permitted to give vent to my irritation at the habit, not at all international in spirit, of expressing all measurements in inches, feet, yards, miles and square miles; in 1980 we are all citizens of the world!

These differences are, it need hardly be said, extremely minor in the context of an overall impression of a highly intelligent work, which has the great merit of linking natural sciences and the humanities.

Let me now turn from these basic issues to make a few remarks on form. As I pointed out at the beginning of this analysis, this is certainly an admirably readable book. It is made so by its style, and by an approach which, though scientific, is always deductive. It is enlivened by the use of entertaining asides, such as anecdotes like those describing how Tom Gray and Donald Johanson discovered Lucy, the context in which Ralph Holloway studied his endocranial casts, or the anxious cleaning of skull 3733 by Alan Walker; and, not least, by the interrogative way which they sometimes use to outline the problems better; the questions asked are precisely those the reader is likely to be asking himself.

We learn by this book that Man is very ancient; his origins, both morphological and behavioural, have deep roots in the animal kingdom. It is by studying this kingdom and systematically analysing all contemporary human societies that we may come up with the answers to questions about our own origins, the process of our evolution and, consequently, to some limited extent, about our future. It is only through a better knowledge of our past and of all that can illuminate it that we may come to be able to foresee, and forestall, our destiny.

Yves Coppens is Co-Director of the Omo and Afar international expeditions, and Deputy Director of the Musée de l'Homme, Paris. 